\title{
How and Why Do Junior Doctors Study? What Materials Do They Use?
}

\author{
Natasha Wiggins, ${ }^{1}$ Sananda Haldar, ${ }^{2}$ and Seema Biswas ${ }^{3}$ \\ ${ }^{1}$ Department of Medicine, Colchester Hospital University NHS Foundation Trust, Colchester, CO4 5JL, UK \\ ${ }^{2}$ Department of Radiology, Brighton and Sussex University Hospitals, Brighton, BN2 3EW, UK \\ ${ }^{3}$ Deapartemnt of Surgery, Ziv Hospital, Safed, 13000 Galilee, Israel
}

Correspondence should be addressed to Seema Biswas; seemabiswas@msn.com

Received 12 November 2012; Accepted 25 December 2012

Academic Editor: Saeed Farooq

Copyright (C) 2013 Natasha Wiggins et al. This is an open access article distributed under the Creative Commons Attribution License, which permits unrestricted use, distribution, and reproduction in any medium, provided the original work is properly cited.

\begin{abstract}
Context. Junior doctors studying for exams need reliable information close at hand. Objectives. We set out to understand the resources junior doctors use to study and revise. Methods. A questionnaire was circulated to junior hospital doctors within a single UK deanery sitting membership examinations, asking what motivates them to study, what resources they use to learn and revise, and what qualities they look for in the ideal learning and revision resource. Findings. We received a $70 \%$ response to the questionnaire (140 out of 200 doctors) and found that nearly all doctors are motivated to study by examinations $(95 \%, n=133)$ and by patients they look after on the wards $(73 \%, n=102)$. Their ideal learning resources comprise case-based learning $(64 \%, n=70)$. They use textbooks at least as much as online resources and learn directly from their seniors. Discussion and Conclusion. To tailor learning and revision resources for junior doctors we need nationwide research on how they learn and revise. This study supports the development of reliable case-based learning material in print and, and the collaboration of educators and junior doctors who have clear ideas about the resources they want to use.
\end{abstract}

\section{Context}

Much has been written about the increasing popularity of online learning amongst medical students and junior doctors and the potential for web-based interactive medical teaching. We know that doctors are more likely to look up answers to problems they encounter in their working day when this is easy to do and online access is, literally, to hand. We know that doctors prefer resources that are fully accessible such as full text journal articles [1], and we know that when it comes to both teaching and learning, a case-based approach is much more effective [2]. We also know that assessment inevitably drives learning [3].

In an attempt to better understand what motivates junior doctors to study and to understand how they use study materials, we performed a questionnaire study in a UK deanery asking junior doctors sitting postgraduate examinations why and how they study and revise.

\section{Objectives}

Our objectives were to understand in more detail the resources junior doctors use today and determine their ideal learning and revision aids.

\section{Methods}

All junior hospital doctors in a single deanery were approached and asked to complete an online questionnaire after a brief explanation. Questionnaires were emailed with permission of the deanery. The deanery administrator provided email addresses. Involvement in the study was not compulsory, and trainees were emailed only once.

They were informed that the objective was to determine their motivators to study and revise, find out what materials they use, what they look for in an ideal learning and revision resource, and that the findings of this research would be published. The research was performed over one month in 


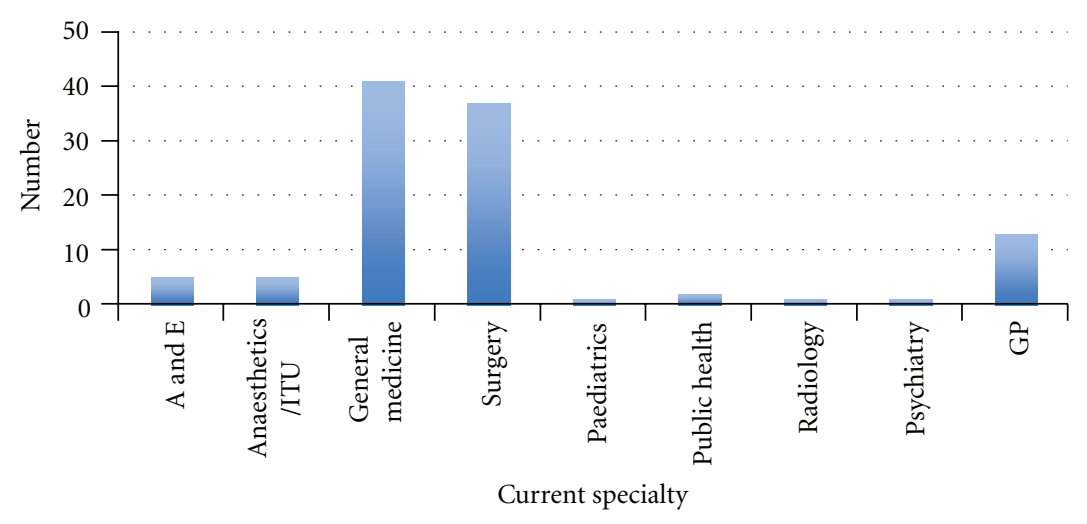

(a) N.B. A and E: Accident and Emergency; ITU: Intensive Care Unit; GP: General Practice

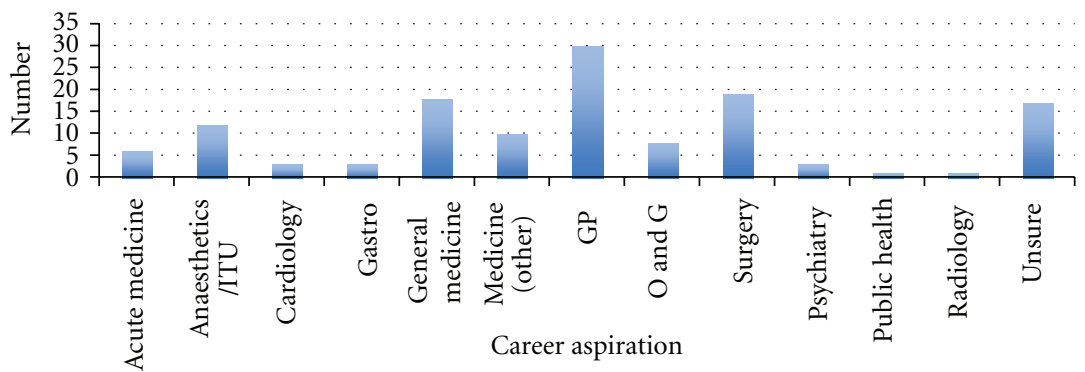

(b) N.B. O and G: Obstetrics and Gynaecology, Gastro: Gastroenterology

FIGURE 1: The current specialties and future plans of the doctors.

2011, and data stored on an excel file accessible only to the authors.

\section{Findings}

We received 140 questionnaire responses out of 200 potential respondents-junior doctors about to sit their membership exams who were eligible to answer (a $70 \%$ return). Trainees were in foundation years 1 and 2 and core training years 1 and 2 .

The current specialties and future plans of the doctors are shown in Figures 1(a) and 1(b).

Most doctors use resources that are close to hand, and Figure 2 shows the popularity of common non-medical websites regarded as sources of encyclopaedic learning.

Motivators to study, Figure 3, were postgraduate membership examinations $(95 \%, n=133)$ and looking up material before changing specialty within rotation $(57 \%, n=80)$. Doctors were, however, well motivated to study after seeing cases on the ward or in clinic $(73 \%, n=102)$ and this coupled with continuous learning $(24 \%, n=33)$ makes a strong case for readily accessible learning materials for doctors at work.

In spite of the reported seismic shift to online learning resources, doctors do still use textbooks, indeed, in this study, the use of textbooks exceeded online materials $(86 \%, n=$ 120 ) but it is clear the junior doctors use multiple resources, perhaps depending on exactly where they are when they study and what they have immediate access to. Doctors prefer to learn from cases and expect the materials they use to

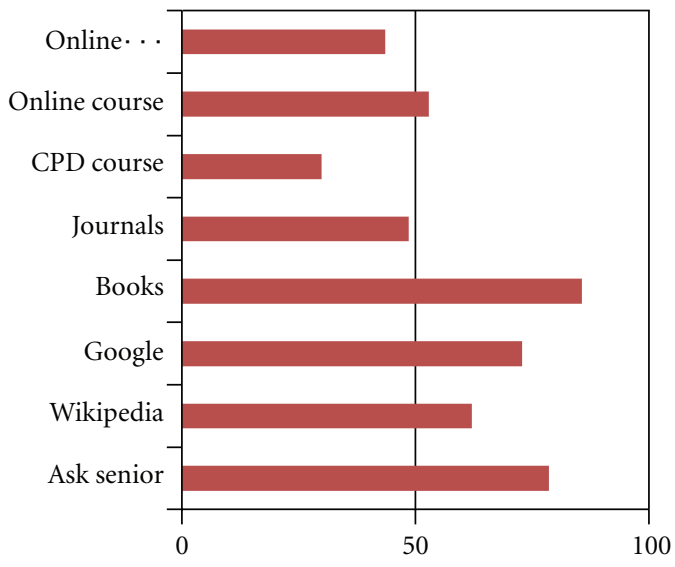

$(\%)$

FIGURE 2: Learning resources the junior doctors use.

be correct, although the latest references are not essential. Perhaps this reflects a need for comprehensive resources that do not require the consultation of references separately; that is, everything you could want to know would be in one place. Likewise, in terms of revision resources, Figure 4, questions with full answers are the single most important factor in revision resources that can also be trusted to be correct.

Continuous learning and reading around interesting cases seems distinct to exam revision that typically begins from 2 to 4 months before an exam. Revision resources are chosen on the advice of peers, the number of questions, the cost, the quality, and similarity of the questions to 


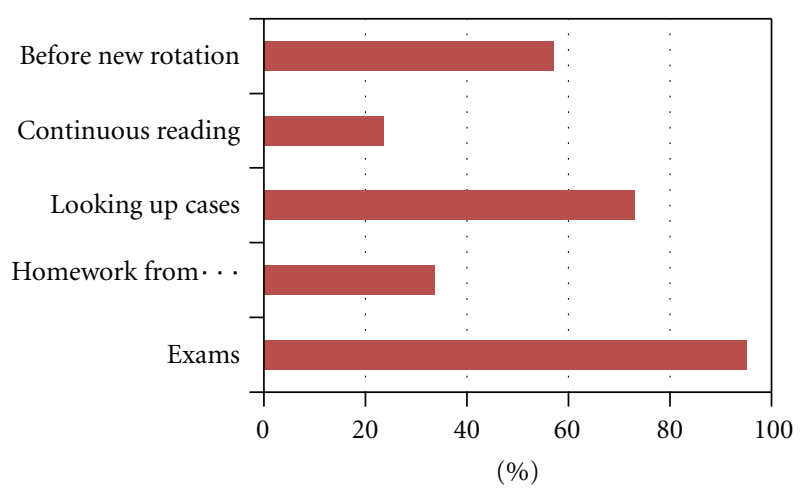

Figure 3: Motivators to study.

exam. Podcasts are surprisingly underused according to this particular study.

\section{Discussion}

Though we make assumptions about an online computer generation of junior doctors, junior doctors do use textbooks at least as much as websites to learn and by no means confine their learning to preparation for examinations. As lifelong learning is now integral to good medical practice [4], resources should be available to help all clinicians find the information they need to remind themselves of the basics and stay up to date. We know that performing a Google search is fairly standard in the way learners enquire about a problem and that this is universal from P.h.D students to school children. This has certainly replaced the classical encyclopaedia but not yet the medical textbook.

Cased based learning is preferred, and looking up cases from the ward or preparing for a new specialty on rotation are key reasons to consult learning resources. This is, indeed, heartening news for clinical teachers and perhaps an opportunity to build on, as web-based materials develop and textbooks are designed to discuss diseases case-by-case rather than the standard systems-based approach. Slotnick [5] describes the process by which doctors learn in response to specific problems, and certainly learning in response to problems encountered on the ward is perhaps what William Osler had in mind when he said

"He who studies medicine without books sails an uncharted sea, but he who studies medicine without patients does not go to sea at all."

Getting learning resources to the bedside is crucial, therefore. Increasingly more trainees have online access on the move. This can only help promote workplace-based learning, and apps for drug formularies are perhaps a perfect example of how technology may improve medical care. Hare et al. [6] describe the development of online case-based learning tools in psychiatry and models for case-based learning. Hare reminds us to keep educational principles (relevance, reliability, and validity of content; clarity of delivery; effective use of the learner's time and choice of the most appropriate assessment tool) paramount, as we design these and Schank [1]

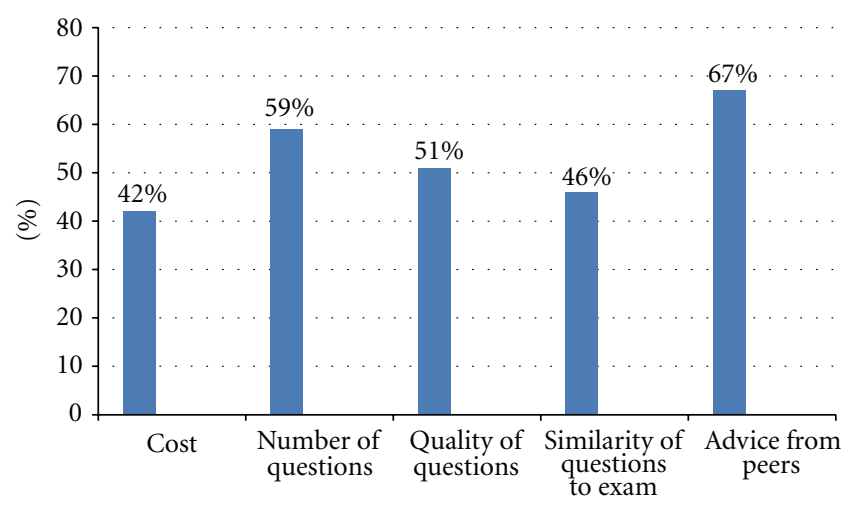

Figure 4: What junior doctors want of a revision resource.

explains why case-based learning is so effective, we effectively tell stories about precisely what the doctor wants to learn and allow doctors to extrapolate this information to their own cases.

The authors' view is that case-based learning simulates learning from real histories and puts doctors in the situation where they have to draw on what they already know to make decisions, while learning new information in clinical (and personal) context-much more memorable than isolated dry facts. This is also an opportunity to integrate basic science and clinical medicine for both lifelong learning and for revision. It seems clear that learners (the junior doctors) and authors of learning resources (experienced teachers) should collaborate on their development.

Although the UK has seen significant changes to the way medical teams are structured with dissolution, to some extent, of teams and the adoption of a shift system of working hours, over $75 \%$ of junior doctors consult their seniors. This is significant, not least, because the question asked is about learning, not seeking help in a clinical situation. Perhaps the apprentice model of learning is not completely dead?

Key to what learning resource is used is accessibility. Books are certainly more comfortable to use, but almost everyone has online access at home. However, more work needs to be done. Perhaps it is time for a nationwide study of how doctors learn, so that we are better able to provide optimal learning and revision resources.

\section{Conclusions}

What motivates junior doctors to study is indeed exam pressure, but this is certainly not the only motivation to learn, and learning is optimally case-based, simulating the clinical environment. Learning resources need to be comprehensive, of high quality and readily accessible at work.

Leaning and Resources Questionnaire

(1) Current career level

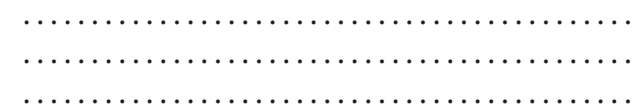


(2) Current speciality if working

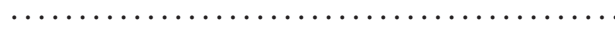

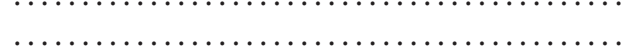

(3) Age

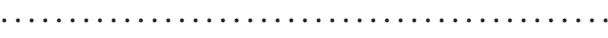

n.m.

(4) University of study/graduation (including country if not UK)

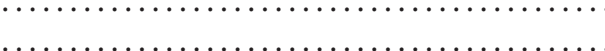

(5) Career aspirations/chosen speciality

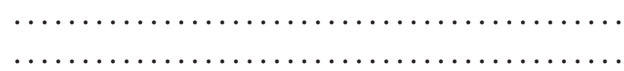

(6) Do you have to pass any exams to progress in your chosen career?
$\bigcirc$ Yes
No
$\bigcirc$ Unsure

(7) Have you passed any yet?

$\bigcirc$ Yes

No

(8) If so what?

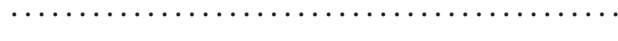

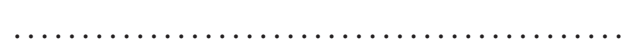

(9) When do you study? (Tick all that apply)
$\square$ Prior to an exam
$\square$ When your boss has set "homework"
$\square$ If you come across something you don't know as much about as you'd like
$\square$ Continuously as you enjoy furthering your knowledge
$\square$ Before starting a new job/rotation
$\square$ Other

(10) If other, please state
(11) How do you learn? (Tick all that apply)
$\square$ Asking seniors
$\square$ Wikipedia
$\square$ Google
$\square$ Books
$\square$ Journals
$\square$ CPD based courses

$\square$ Online courses for example, BMJ Learning

$\square$ Online assessment for example, Learning for Healthcare, exam revision websites

$\square$ Other

(12) If other please state

(13) How do you revise? (Tick all that apply)
$\square$ Physical course
$\square$ Online course
$\square$ Exam revision website
$\square$ Online teaching for example, BMJ Learning, university websites
$\square$ Text books
$\square$ Revision books
$\square$ Question books
$\square$ Orally with friends/colleagues
$\square$ Other

(14) If other please state

(15) What do you like about what you use?

(16) What do you dislike about the ones you use?

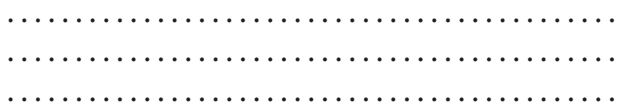

(17) What do you like about what you don't use? 
(18) What do you dislike about what you don't use?

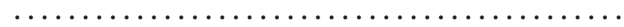

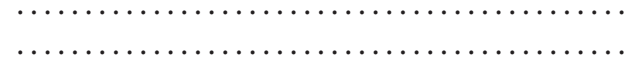

(19) What do you look for in the ideal LEARNING resource?

$\square$ Case based examples

$\square$ Latest references

$\square$ Material you trust to be correct

(20) What do you look for in the ideal REVISION resource?

$\square$ Answers with full explanations

$\square$ Latest referencing

$\square$ Material you trust to be correct

(21) How long before an exam do you usually start revising?

More than 6 months

4-6 months

2-4 months

2 months

$\bigcirc 1$ month or less

(22) Have you ever used online teaching for example, via a university website, BMJ Learning

$\bigcirc$ Yes

No

(23) If yes, which ones?

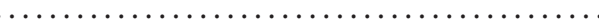

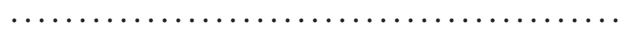

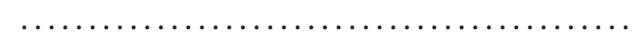

(24) What did you like about them?

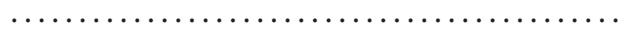

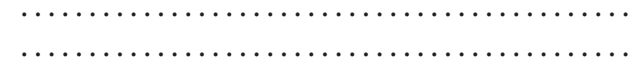

(25) What did you not like about them?

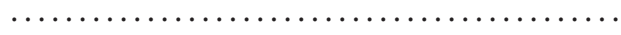

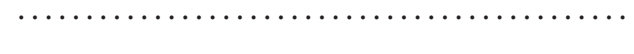

(26) Have you ever used a revision website?

$\bigcirc$ Yes

No
(27) If yes, which one?
$\square$ http://www.onexamination.co.uk
$\square$ http://www.pastest.co.uk
$\square$ http://www.passmedicine.com
$\square$ http://www.medrevise.co.uk
$\square$ http://www.medicalrevision.org
$\square$ http://www.medicalfinals.co.uk
$\square$ http://www.yoracle.com
$\square$ http://www.passmed.co.uk
$\square$ http://www.almostadoctor.com
$\square$ http://www.scrubbingup.com
$\square$ http://www.acemedicine.com
$\square$ http://www.specialtyexam.com
$\square$ http://www.examdoctor.co.uk
$\square$ other

(28) If other please state

(29) Why did you choose the one you chose?

$\square$ Cost

$\square$ Number of questions

$\square$ Quality of questions

$\square$ Similarity of questions to exam

$\square$ Advice from peer

(30) Have you ever used podcast?

Yes

No

(31) If so, which?
$\square$ Podmedics
$\square$ Podomatic
$\square$ http://www.Dr-podcast.co.uk

Thank you so much for taking the time to slog through that! Much appreciated, have a lovely day.

\section{Disclosure}

S. Biswas is a general surgeon and tutor in medical education and global health. She is a former senior examiner at Kings College Hospital Medical School, UK (now relocated to Israel) and is the former editor of onExamination from BMJ Learning. This research has not been shared with colleagues at onExamination nor BMJ Learning and does not represent market research. 


\section{References}

[1] K. Romanov and M. Aarnio, "A survey of the use of electronic scientific information resources among medical and dental students," BMC Medical Education, vol. 6, article 28, 2006.

[2] R. C. Schank, "Case-based teaching: four experiences in educational software design," Interactive Learning Environments, vol. 1, no. 4, pp. 231-253, 1990.

[3] W. A. Reid, E. Duvall, and P. Evans, "Can we influence medical student's approaches to learning?” Medical Teacher, vol. 25, pp. 401-407, 2005.

[4] J. Collins, "Education techniques for lifelong learning: lifelong learning in the 21st century and beyond," Radiographics, vol. 29, no. 2, pp. 613-622, 2009.

[5] H. B. Slotnick, "Physicians' learning strategies," Chest, vol. 118, pp. 18S-23S, 2000.

[6] E. H. Hare, P. Evans, C. E. McIntosh, and L. D. G. Thomson, "Case-based online learning for medical undergraduates," Psychiatric Bulletin, vol. 31, no. 2, pp. 73-75, 2007. 

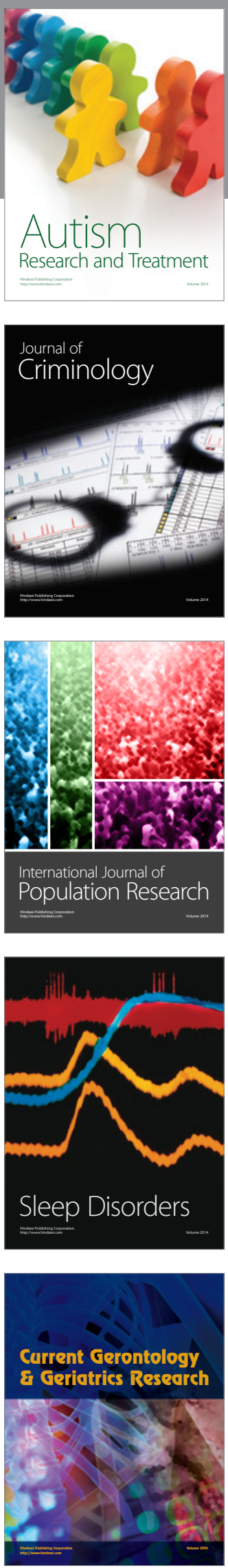
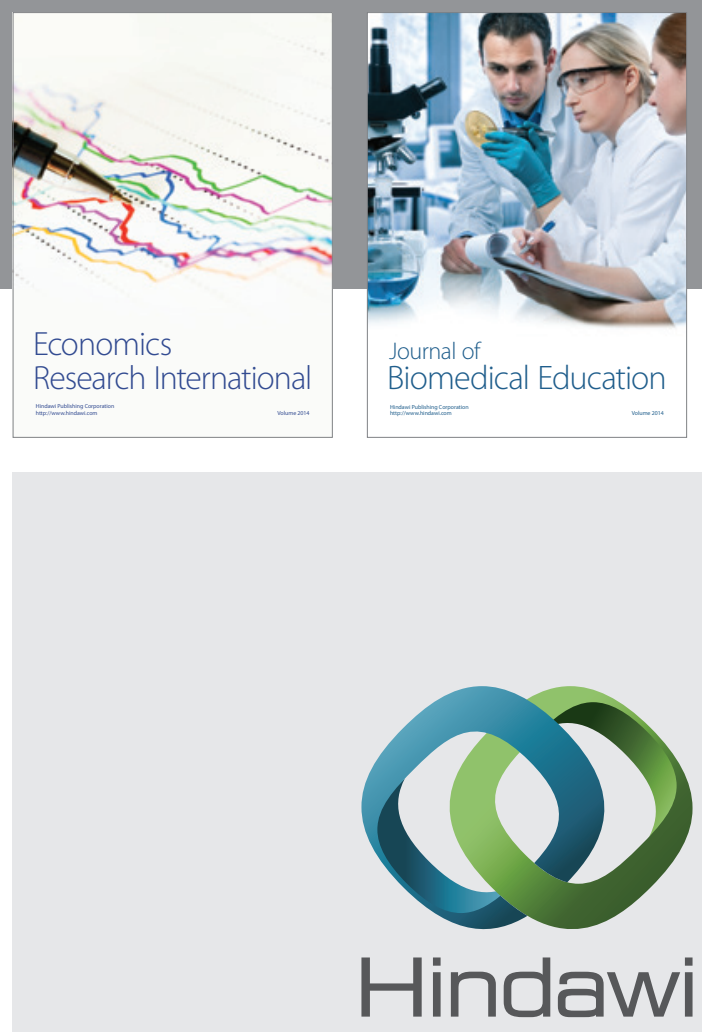

Submit your manuscripts at

http://www.hindawi.com
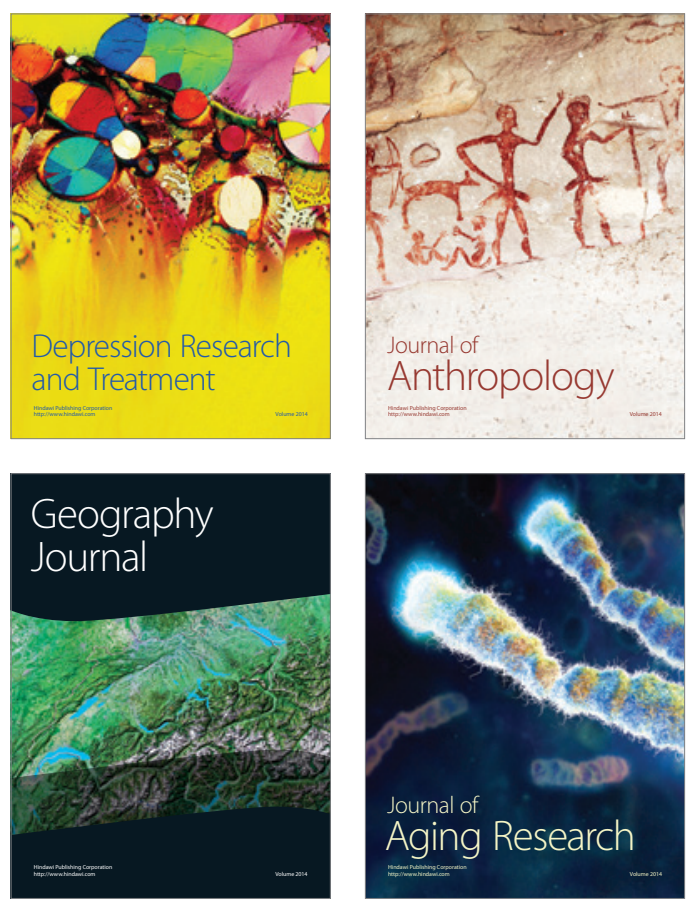
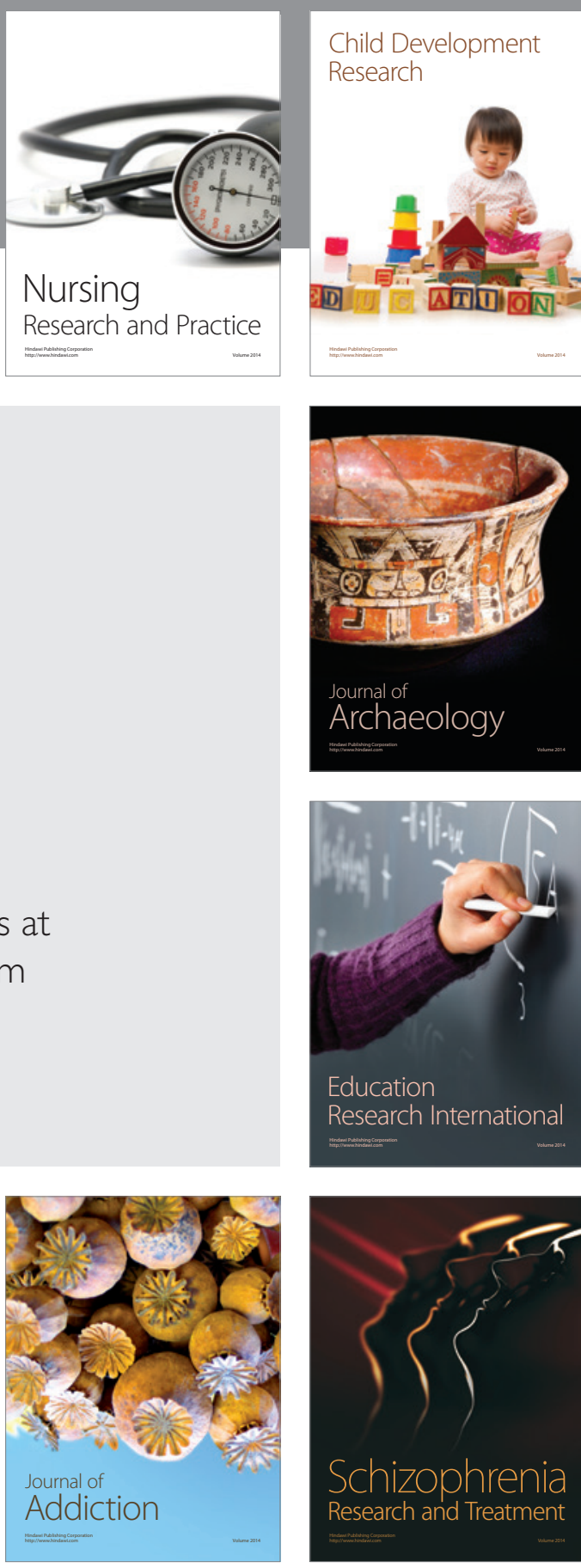

(D)
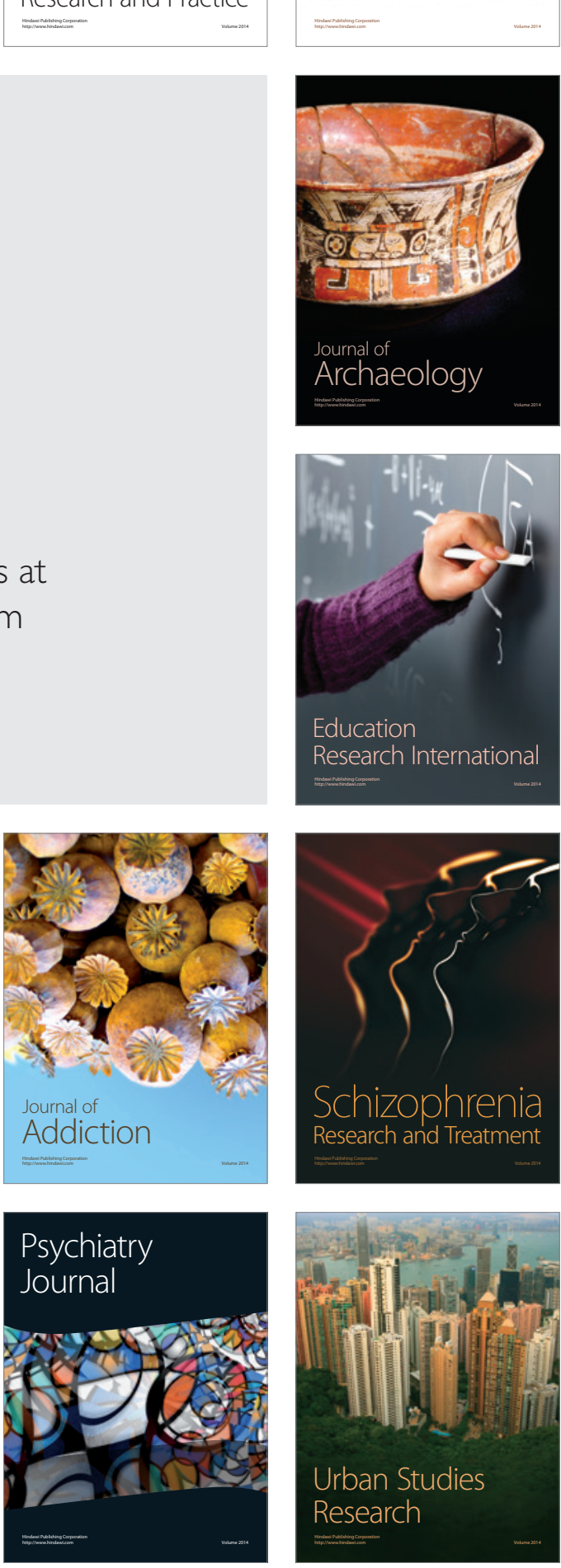